\title{
INTERVIEW
}

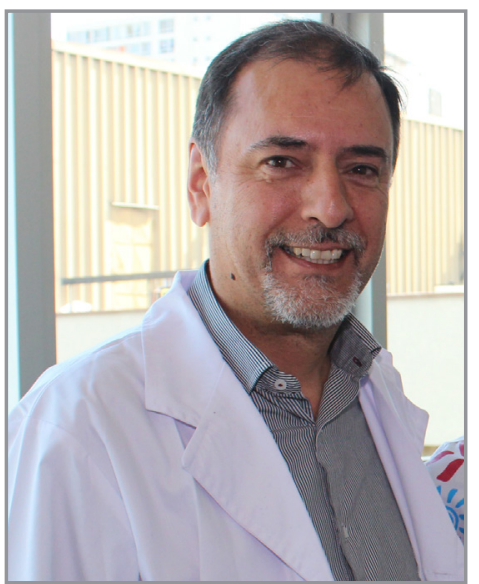

\section{The inventor of the Rotating-Disk Sorptive Extraction technique kindly spoke to BrJAC}

\author{
Pablo Richter $(10$ \\ Full Professor \\ Department of Inorganic and Analytical Chemistry \\ Faculty of Chemical and Pharmaceutical Sciences \\ University of Chile, Santiago, Chile
}

Pablo Roberto Richter Duk is Full Professor at the University of Chile and current Academic Director of the Faculty of Chemical and Pharmaceutical Sciences (FCPS) at the same University. He has been the Director of the two Internationalization projects of the FCPS (periods 2016-2018 and 2020-2022).

Prof. Pablo Richter was born in Santiago, Chile and obtained his Bachelor's degree in Chemistry (1984) and his PhD degree in Chemistry (1991) from the University of Chile. Between 1991 and 1992 he carried out postdoctoral studies at the University of Córdoba, Spain, and in 1996 at Oklahoma State University, USA. In the period 1997-2003, Prof. Richter directed the environmental laboratories of the National Center for the Environment (CENMA) at the University of Chile and has visited different environmental institutes in Japan (1998) under the CENMA-JICA international cooperation project. He was also Director of the Center for Studies in the Development of Chemistry (CEPEDEQ) in the period 2003-2015 and was Director of Postgraduate Studies of the FCPS in the period 2010-2018.

His main lines of research and scientific interest are food and environmental sample preparation, microextraction technologies, chromatography, mass spectrometry, and electroanalysis. He is the inventor of the sample preparation technique "Rotating-Disk Sorptive Extraction", RDSE. In the period 2017-2019, he was a member of the Superior Council of Science of the National Fund for Scientific and Technological Development (FONDECYT). He also joined the chemistry study group at FONDECYT (periods 2004-2007 and 2015-2016), becoming its Director in 2016. He has been a responsible researcher and co-researcher in FONDECYT and in international research projects (Spain, Japan, Argentina, Colombia), an evaluator of research projects for FONDECYT, CORFO and universities, and a member and chair of the Organizing Committee and Scientific Committee at different Congresses.

He is the author or co-author of 134 scientific papers in journals of international circulation (ISI), has been cited more than 2700 times and has an " $h$ " index of 31 . He is a frequent reviewer of scientific papers published in several WoS journals and is a member of the editorial committee of the Journal of Analytical Methods in Chemistry and Advances in Environmental Chemistry. He has given lectures by invitation in Chile, Brazil, Argentina, Spain, Ecuador, Peru, Colombia, Uruguay, Mexico and Germany and has been selected by the Chilean Academy of Sciences as "Researcher of the Frontier Science Program 2004-2006". Since 2009 he has been a member of

Cite: Richter, P. The inventor of the Rotating-Disk Sorptive Extraction technique kindly spoke to BrJAC. Braz. J. Anal. Chem., 2021, 8 (30), pp 3-8. doi: http://dx.doi.org/10.30744/brjac.2179-3425.interview.prichter 
the Area Committees of the Advanced Human Capital Program of CONICYT. He has belonged to the following scientific societies: the Chilean Chemistry Society, the Analytical Chemistry Division of the Chilean Chemistry Society, IUPAC, the International Society of Electrochemistry, AOAC and RACAL. He has been president for two periods of the Division of Analytical and Environmental Chemistry of the Chilean Chemical Society, "Observer" in the Division of Analytical Chemistry of the Federation of European Chemical Societies and Professional Institutions (DAC-FECS) and a member of the International Ibero-American Steering Committee of Analytical Chemistry.

Prof. Richter has been a peer evaluator in accreditation processes for the Bachelor of Chemistry programs in Argentina and Ecuador (CONEAU) and in Master's and Doctorate programs in Chile (CNA). He has taught undergraduate and postgraduate courses at the University of Chile and has directed theses for the Bachelor's degree (43), Master's degree (5), Doctorate (17) and two postdoctoral works at the same university.

Currently, Prof. Pablo Richter advises and teaches postgraduate courses in the area of analytical laboratory accreditation, validation of methods, and techniques for sample preparation. He has also carried out accreditation audits as a technical evaluator for the National Institute for Standardization.

How was your childhood? When was your first contact with the scientific area?

I had a very normal childhood, rather far from science. As a child my first interest was sport; I didn't like school very much. My life then turned around soccer and tennis; I was pretty good at both sports. I am the youngest of the family. My father was an industrial technician and had a blanket and yarn factory and my mother was a housewife, buy she had studied Medicine at the University of Chile. I have two siblings, a woman and a man. My first contact with science was through an experiment at school that I never forgot; I think it was one of the first experimental activities I did. The aim was to demonstrate the conductivity of drinking water using a pair of graphite electrodes connected to a light bulb.

What early influences encouraged you to study science? Did you have any influencers, such as a teacher?

I remember that my interest in chemistry began three years before finishing high school, but I was mainly interested in teaching. I was passionate about the ways of teaching adopted by my chemistry teacher, Prof. Alejandro Donoso. It was the only course on which I totally concentrated, I could understand everything, and I started to get very good marks in the subject. Although at school I was never very dedicated to study, when I came home after chemistry classes I studied the class on my blackboard and explained it to myself like a teacher, I loved to draw molecules and chemical equations and explain the changes that were happening through those reactions.

When did you decide to go into the field of chemistry? What motivated you? How was the beginning of your career in chemistry?

Linking with the previous answer, at that time, I first decided to study chemistry education. During my last year of high school, I researched more about chemistry careers at the different universities in the country. I realized that in addition to chemistry education I had the possibility to study for a licentiate degree in chemistry (this degree in Chile is an intermediate between Bachelor's and Master's), which prepares university researchers who can also teach chemistry at the university. So, I applied to all universities to follow this career. Fortunately, I was accepted by the University of Chile in 1980.

The first year of my degree was very hard, very difficult, not only regarding the chemistry course but we also had to study mechanics, algebra and calculus together with the undergraduate students of physics. We started with 50 students in the first year and 10 remained in the second year. At that time, that failure rate was totally normal, even more so in a science faculty. 
What has changed in the student's profile, ambitions and performance since the time you started your career?

There are considerable differences between the students of the 1980s and those of today. Various aspects and changes have been very positive in this evolution; however, I also see some negative changes.

In general terms, people in different areas of life have rights and duties that should be in a fair balance. In my student days at the university everything turned in the sphere of obligations and duties and we were little concerned about our rights as students. If $80 \%$ of the students failed in a subject, the problem was always the fault of the students and nobody thought to question the teaching capacity of the teachers. Today this has changed, driven mainly by the processes of quality assurance and accreditation of careers and universities.

In this context, in my opinion, the balance that in the 80 s was displaced towards the obligations or duties of students was reversed in the last decade and displaced towards rights. Although this transition seems totally fair, one realizes that on many occasions it goes to the other extreme. Students themselves must understand that balance is ideal and that duties are also essential in life.

\section{What is it like to be a university professor? What advice would you give to a young scientist who wants to pursue a career in chemistry? \\ The academic work at the University is very diverse; a professor must do teaching, research, extension and university administration. It is different from working in a research institute, where that unique function is mainly carried out. I really like this variety of tasks and especially the combination of teaching and research that is the basis of the training of new researchers. I am very happy at the University and I consider myself privileged to do what I like. To young people who want to pursue a scientific career, I would say that they should do their work with all seriousness and rigor, and that they should have a holistic vision, since the best way to approach a scientific problem is from an interdisciplinary or transdisciplinary point of view. Furthermore, science today requires solving problems by working as a team.}

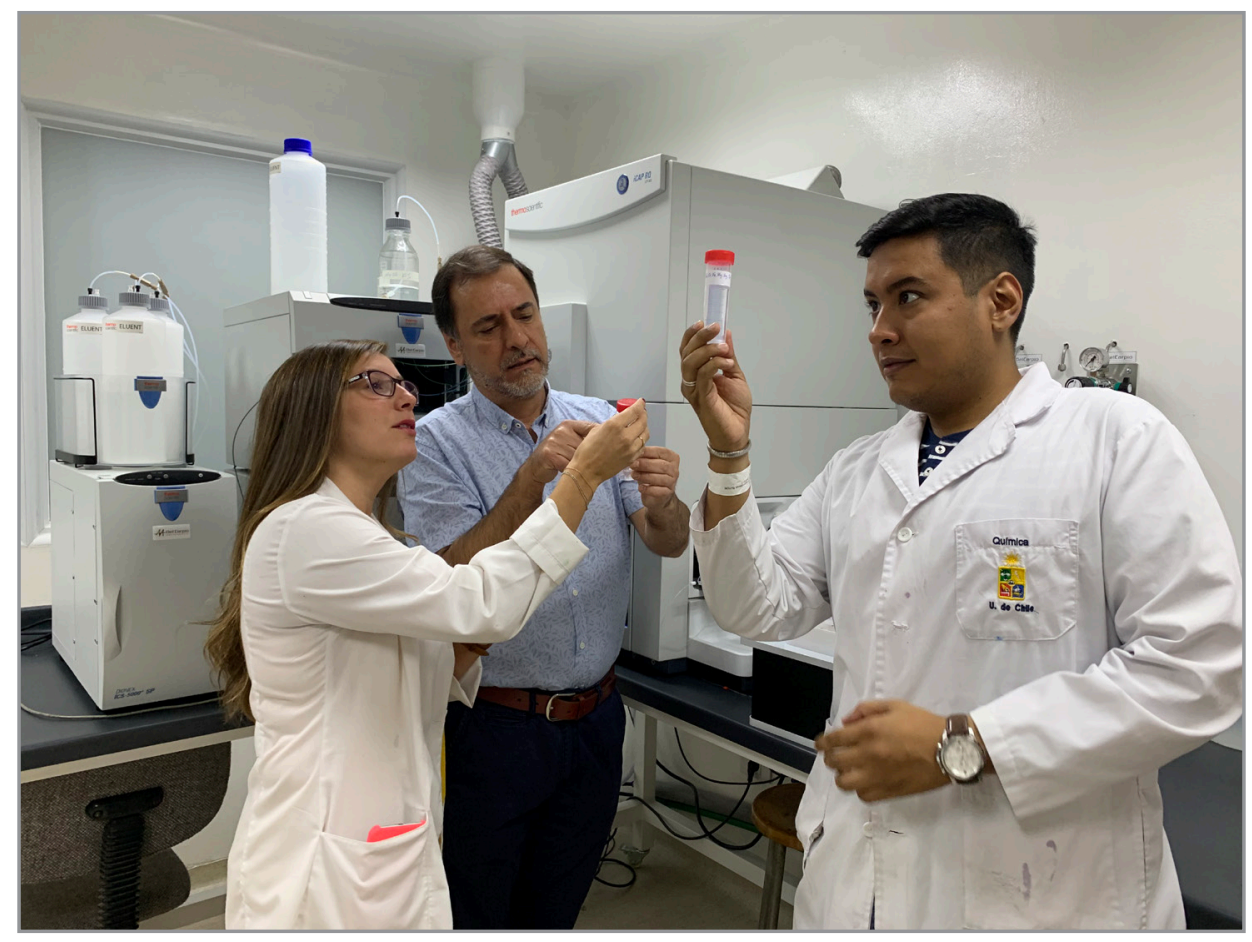

From left to right: Dr. Valentina Manzo, Prof. Dr. Pablo Richter, Dr. Daniel Arismendi at the laboratory of ICP-MS. 
What do you think is the importance of the scientific journals? Tell us a little about your work in this area.

The results of scientific research must be divulged. At this level, scientific journals are essential to show the advances in knowledge, but through rigorous peer-review processes.

In my opinion there are a number of aspects that should be analyzed and improved in the field of publications in scientific journals. Just to mention a couple of aspects: Firstly, the manuscript evaluation procedure, although not in crisis does not work fully satisfactorily at present. I perceive sometimes a lack of commitment to this system by many scientists; many researchers don't even respond to the email invitation to review. It should be a mandatory system; if a researcher submits papers to a journal to be published, they should be willing to evaluate a certain number of manuscripts per year. Some journals demand that commitment. Another relevant aspect related to scientific journals is the full access to manuscripts. I think that knowledge should be universally disclosed and, in this sense, the open access alternative is very attractive, but today its cost is very high. I think that all editorials should tend to open up to this option, understanding that financing is a key aspect that should be solved.

Tell us a little about the importance of the National Fund for Scientific and Technological Development (FONDECYT) and what is it like for you to be a member of it.

I can mention that FONDECYT is the program that distributes most of the resources for science in Chile. The main programs are: postdoctoral positions (3 years), initiation projects (3 years) and regular projects (4 years). A big problem occurring in Chile is that the budget for science, technology and innovation represents only $0.36 \%$ of GDP. This value urgently needs to be increased, primarily because there is a group of researchers of a very good scientific level who do not get funding to carry out their research proposals. This proportion has been relatively stable since 2011 , which may be due to other areas being prioritized and the lack of clear strategies and policies. Fortunately, since approximately 1 year ago Chile has had a new Ministry of Science, Technology, Knowledge and Innovation. We hope that this new ministry will be endowed with human and material resources so that it can fulfill the expectations that have been generated in the scientific world.

I was for 3 years (2017-2019) a member of the Superior Council of Science of FONDECYT representing the Chemistry area. It was an honor to participate in this independent academic body, which nowadays was replaced in the structure of the new ministry.

How was it for you to be the Director of the environmental laboratories at the National Center for the Environment (CENMA) at the University of Chile?

The National Environment Center (CENMA) was a project agreed between the governments of Chile and Japan to create a center of reference in the environment. This project was delegated to the University of Chile for its execution and Prof. Eduardo Schalscha (a prestigious Chilean researcher in environmental chemistry) invited me to participate. I was in charge of the laboratories of this institution between 1997 and 2003. The project involved setting up a top-tier analytical environmental laboratory with equipment funded by the Japanese government and resources for the operation funded by the Chilean side.

"For me, being the Director of CENMA was a very important challenge because it involved setting up and then running a very complete analytical laboratory in all areas of
The Japanese side also provided short- and long-term experts from Japan. The research activities to be carried out in the CENMA project were defined in the document "Record of Discussion, RoD", agreed between both governments when creating the center. For me it was a very important challenge because it involved setting up and then running a very complete analytical laboratory in all areas of the environment and with the best equipment in the country, together with a team of carefully selected young chemists from the country. Undergraduate and postgraduate students also participated of the project. The investment in laboratory instruments was of the order of 6 million dollars. It was a very important period in my life, in which I had the opportunity to learn a lot, not only 
about instrumentation and analytical techniques but also about laboratory management. We also had to learn from sampling campaigns and the analysis of air, water and hazardous waste samples. A central objective of the laboratories during the first years of operation (1998-1999) was the implementation of a quality assurance system and its accreditation according to ISO 17025 for more than 80 parameters in environmental matrices.

Could you comment briefly on the recent evolution of Analytical Chemistry, especially in your areas of activity, environment and food, considering your contributions?

Analytical chemistry has seen an important evolution during the last decades, not only in instrumentation but also in new strategies of sample preparation. By means of sample preparation, the analyte is extracted and preconcentrated from a sample to be measured by an instrumental technique practically free from matrix interferences. Since 1990 a sharp increase in the number of publications has been seen covering this area, describing different analytical strategies in different fields of analytical chemistry. Particularly important has been the introduction of solid phase microextraction (SPME) in 1989 by Pawliszyn et al. which produced an inflection point in the evolution of microextraction techniques and the advent of different strategies of sample preparation for organic analytes in different kind of samples such as environment, food and biological samples, making possible the quantification of analytes at concentrations at the level of ppt or ppq. Our contribution in this area has been related to microextraction technology based on RotatingDisk Sorptive Extraction.

\section{You have published many scientific papers. Would you highlight any?}

Several papers have been very important to me during my academic life at the University of Chile. My first paper was in 1984 during the last year of my chemistry degree. Although my supervising professor, Dr. Alfonso Morales, wrote it, I felt that my work was contained there, in an international publication. I read it many times.

- "Polarographic Behaviour and Determination of Nitrofurantoin Chloramphenicol and Related Compounds". Morales, A., Toral, M.I., and Richter, P., Analyst, 1984, 109, 633.

Other important works were those carried out during my PhD program and during my postdoctoral positions. Some representative paper in this category are:

- "Voltammetric Study of 7-Nitro-1,4-Benzodiazepin-2-ones and their acid Hydrolysis Products, 2-Amino-5Nitrobenzophenones". Richter, P., Morales. A., and Lahsen, J., Analyst, 1990, 115, 409.

- "Integrated FIA/HPLC Method for Preconcentration and Determination of Transition Metal lons". Richter, P., Fernandez, J.M., Luque de Castro, M.D. and Valcárcel, M., Chromatographia, 1992, 34, 445.

- "Immobilized Enzyme Reactors: Diffusion/Convection, Kinetics, and a Comparison of Column-Packed and Rotating Bioreactors for Use in Continuous-Flow Systems". Richter, P., López-Ruiz, B., Sánchez-Cabezudo, M., and Mottola, H., Analytical Chemistry, 1996, 68, 1701.

I would also like to highlight these articles that cover different areas of analytical chemistry:

- "Screening and Determination of Pesticides in Soil Using Continuous Subcritical Water Extraction and Gas ChromatographyMass Spectrometry". Richter, P., Sepúlveda, B., Oliva, R., Calderón, K., Seguel, R., J. Chromatogr. A, 2003, 994, 169.

- "Total Element Concentration and Chemical Fractionation in Airborne Particulate Matter from Santiago, Chile". Richter, P., Griño, P., Ahumada, I., Giordano, A., Atmospheric Environment, 2007, 41, 6729.

- "Flow injection photometric determination of zinc and copper with Zincon based on the variation of the stability of the complexes with pH". Richter, P., Toral, M.I., Fuenzalida, E., Tapia, A.E., Analyst, 1997, 122, 1045.

And finally, I must highlight the first work in which we introduced the RDSE technique, given that it opened up a very solid research line with international recognition.

- "Rotating-Disk Sorptive Extraction of Nonylphenol from Water Samples". Richter, P., Leiva, C., Choque, C., Giordano, A., Sepúlveda, B., J. Chromatogr. A, 2009, 1216, 8598. 


\section{How was the process for creating the sample preparation technique "Rotating-Disk Sorptive} Extraction" (RDSE)?

Regarding this process there are two important points to highlight. In 1996 I did a postdoc at Oklahoma State University, with Prof. Horacio Mottola. The aim of this work was to demonstrate the greater efficiency of rotating bioreactors compared to microcolumn packed reactors in continuous-flow systems. The rotatingdisk reactors afforded a significantly more efficient utilization of immobilized active sites of the enzyme and permitted the effective use of very small amounts of biocatalysts. On the other hand, by studying the Stir Bar Sorptive Extraction (SBSE) technology and focusing on the drawback of the twister device, I realized that a disk-shaped device, where the sorbent phase can be fixed on one of its surfaces, solves many of the deficiencies of SBSE. The extraction device used in RDSE uses an extraction phase with a high surface-area-to-volume ratio and can be stirred at much higher velocities than the twister used in SBSE without damaging the phase because the extraction phase is in contact only with the liquid sample. Thus, higher rotating velocities facilitate analyte mass transfer to the sorptive surface. With this in mind, we got to work with my students until RDSE was a reality. In addition, the costs involved in RDSE are significantly decreased because the device can be reused many times by changing the phase according to the nature of the analytes and samples.

"A scientist of my age has lived through a period of great changes and evolution in analytical chemistry. Among many developments I would highlight two relevant features: ..."
For you, what have been the most important recent achievements in analytical chemistry research? What are the landmarks?

A scientist of my age has lived through a period of great changes and evolution in analytical chemistry. Among many developments I would highlight two relevant features: on the one hand, the evolution

of mass spectrometry has been very important and has been marked by an ever-increasing number of its applications in science and technology in all areas of analytical chemistry (inorganic, organic, biochemical) and its successful applications to a variety of analytical problems; on the other hand, the development of sensors is another relevant topic in analytical chemistry that is in full development. Although this topic still needs much development ahead of its robust application in real samples, I highlight it because in the future it will allow us to minimize and simplify the sample preparation stages so that the measurements are increasingly direct and fast.

\section{For what would you like to be remembered?}

In general, I would like to be remembered for being a good person, whether by those close to me or not. This means that the merits are valued more than the defects. In the case of science and the university sphere, as a scientist who contributed honestly to the formation of many professionals and scientists.

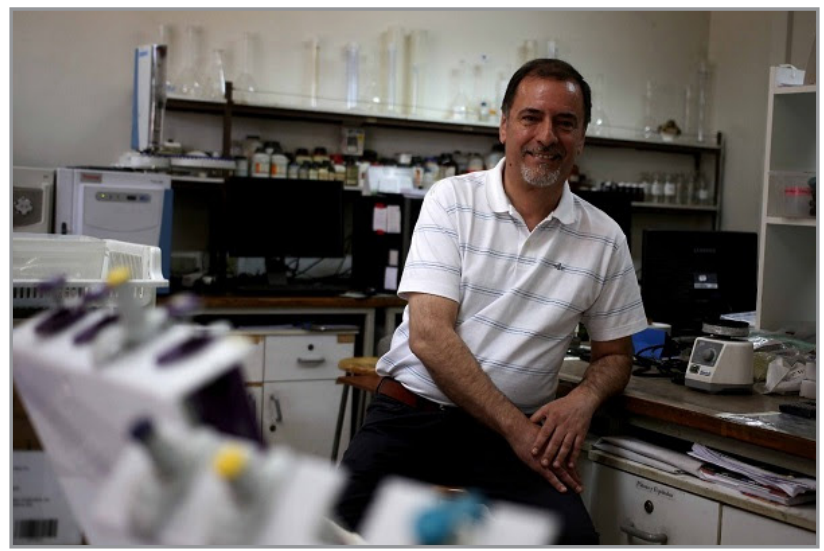

Prof. Dr. Pablo Richter at the laboratory of Environmental Chemistry at the Faculty. 